\title{
3 Research S guare \\ Determinants of Dietary Practice among Type 2 Diabetic Patients: Institution based cross-sectional study
}

\section{Derese Tamiru Desta}

School of Nutrition, Food Science and Technology https://orcid.org/0000-0001-5503-5751

Mignote Gebre Michael ( $\nabla$ mgwish7@gmail.com )

Wolaita Sodo University

Dejene Hailu

Hawassa University

Menen Zegeye

Hawassa University

\section{Research Article}

Keywords: Type 2 diabetes, Dietary practice, Diabetes Mellitus Education

Posted Date: March 29th, 2021

DOl: https://doi.org/10.21203/rs.3.rs-373495/v1

License: (c) (1) This work is licensed under a Creative Commons Attribution 4.0 International License.

Read Full License 


\section{Abstract \\ Objectives}

Dietary management is considered to be one of the cornerstones of diabetes care. There is a lack of data on the dietary practice of diabetic patients, which underestimates its role in the management of diabetes. Hence, this study assessed the level of dietary practices and their associated factors among Type2 diabetic patients in Hawassa city, Sidama Region, Ethiopia.

\section{Results}

Nearly forty-seven percent (46.8\%) of the patients had poor knowledge about diabetes. More than half of the respondents (54.5\%) were overweight and obese. The levels of dietary practice among $171(44.2 \%)$ type 2 diabetic patients were poor. Very low monthly income [AOR $=4.87 ; 95 \% \mathrm{Cl}:(1.20-19.81]$, taking insulin regimen $[A O R=2.36 ; 95 \% \mathrm{Cl}:(1.13-4.91)]$, taking both insulin injection and oral medication [AOR $=11.26 ; 95 \% \mathrm{Cl}:(3.05-41.54)]$, not getting $\mathrm{DM}$ education in hospital $[\mathrm{AOR}=2.72 ; 95 \% \mathrm{Cl}:(1.08-6.85)]$, despondency $[\mathrm{AOR}=3.71 ; 95 \% \mathrm{Cl}:(1.39-9.89)$, lack of support from family and friends about dietary plan $[\mathrm{AOR}=5.64 ; 95 \% \mathrm{Cl}(2.66,11.92)]$, unavailability of fruits and vegetables[AOR $=3.04 ; 95 \% \mathrm{Cl}:(1.11-8.34)]$ were the factors significantly associated with the poor dietary practice.

\section{Introduction}

Diabetes mellitus (DM) is metabolic disorder characterized by abnormality of carbohydrate, fat and protein metabolism and high blood glucoses level which results from defect of insulin secretion, action or both(1) (2). DM is one of the rapidly increasing non-communicable diseases and an important public health problem all over the world(3) (4). Recent estimates from the 2013 International Diabetes Federation [IDF] suggest that the number of adults living with diabetes in the world will rise from 382 million in 2013 to 592 million in less than 25 years(5).

The treatment of diabetes should start with non-pharmacological therapies such as lifestyle interventions. A healthy lifestyle with regular physical activity and healthy eating are very important tools in reaching and maintaining an adequate glycemic control in patients with type 2 Diabetes(6). Dietary management is considered to be one of the cornerstones of diabetes care. It is based on the principle of healthy eating in the context of social, cultural and psychological influences on food choices(7). Good diabetes management is a balance between healthy eating, exercise and medication(8). Dietary management among Type 2 diabetes patients is one way to prevent or delay the long term effect of the condition. Diabetic individuals worldwide are routinely advised to adopt a healthful eating behavior, which requires modifications in food habits, beliefs and meal patterns on a lifelong basis (9). However, despite this effort, Ethiopia is still registering increasing numbers of people being diagnosed with the disease. Dieticians and Nutritionists as well as Health professionals need to be informed on the 
relationships between psychosocial factors and dietary practice among these patients. This will improve their capacity to manage the Type 2 diabetes condition better.

The World Health Organization (WHO) estimates that Diabetes mellitus affects at least 285 million people and causes 3.2 million deaths, six deaths every minute and 8700 deaths every day, and this figure will increase by $70 \%$ in developed countries, and by $42 \%$ in developing countries by $2030(10)$. Increasing sedentary lifestyles, coupled with rapidly growing urban cultures and modified diets, are predicted to triple the prevalence of diabetes mellitus in the next 25 years(11) (12).

Diabetes in sub-Saharan Africa greatly increases the risk of serious, costly complications including emotional distress, heart attack, stroke, kidney damage, blindness, neural damage leading to amputation, and also reduced life expectancy(12). In Ethiopia, national data on prevalence and incidence of diabetes are lacking(13). However, patient attendance rates and medical admissions in major hospitals are rising. In Ethiopia IDF estimated the national prevalence of DM 4.36\%, but community-based survey in Ethiopia suggested even greater prevalence of diabetes. Community based cross sectional study conducted among adults 35 years and above in Gondar, Ethiopia, found prevalence of diabetes $5.1 \%$ in urban and $2.1 \%$ in rural(14). The cost for patient attendance rates and medical admissions in most hospitals of Ethiopia are rising for Diabetic management. Access to diabetes care in the country does not however meet the increments in the incidences and complications of the disease. A conditions where Diabetic patients visiting clinics regularly and their blood glucose levels still remain high despite the treatment they receive is a problem that calls for attention and self-care is the patient responsibility to preserve his/her quality of life (15) (1) (16). (16)

The main treatments goal for patients with diabetes are to prevent or minimize the acute or chronic complications and to reduce serious morbidity and mortality and loss of productivity mainly by following the self-care practices which include regular exercise, taking recommended diet, proper intake of prescribed medications, life style modifications and blood glucose monitoring(1).

Until now, few studies have been reported regarding association between dietary habits, glycemic control, mainly focusing on factors associated with dietary practice and barriers on dietary practice among type 2 DM patient. In developing countries like Ethiopia where urbanization is expanding, lifestyles are changing, literacy rate is low, and people are still living in poverty, DM and its impact on development and health is particularly critical. In Ethiopia incomplete routine health information and lack of data on the proper dietary practice of diabetic patients affect the long term management of diabetes. These diabetic patients are facing difficulty in choosing food items when they feel like eating. They also fail to decide how much to eat whenever necessary. At the same time their care givers also fail to identify food items to be included in the diabetic meal and how to prepare them.

\section{Methods}

\section{Study setting}


This study was conducted at the outpatient department of Adare General Hospital in Hawassa City, South Ethiopia. Adare General Hospital is located in Hawassa city, $270 \mathrm{~km}$ south of Addis Ababa, Ethiopia, at an average altitude of $1,708 \mathrm{~m}$ above sea level. The hospital is selected purposively because of wellorganized regular DM case follow-up and large number of type 2 DM case flow-in Diabetic Clinic.

The hospital provides range of services in its outpatient units including follow-up for chronic illness, family planning, maternity services, emergency, inpatient services, surgery, and others services. Adare General Hospital serves an average 250 to 300 patients daily. The diabetic unit is one of the specialty units of the hospital, which provided services for a total of 3600 Type 2 diabetes patients in 2015. The diabetic follow-up clinic gives service for 50 - 90 type 2 DM patients per day for three days of a week that is Tuesday, Wednesday and Friday.

\section{Study design and population}

An institution-based quantitative cross-sectional study was employed. The study population was selected type 2 DM patients attending or visiting out patients department of Adare General Hospital at the period (time) of data collection.

\section{Sample Size and Sampling Technique}

Sample size was determined using double proportion formula via Epi info 7 software based on previous study(16). Despondency was considered as associated factor with exposed proportion of $68.2 \%$, unexposed proportion of $53.2 \%$, odds ratio of 1.8 and $10 \%$ non- response rates. Therefore, the final total sample size was 394 DM patients.

Systematic sampling technique was employed to recruit the study participant from the selected facilities based on the flow rate during the study period that come for follow up during a month preceding the data collection. The sampling interval ' $k$ ' was obtained by dividing the sampling proportion in one month's $(\mathrm{N})$ to the number of sample(n) at data collection site $\left(n^{\prime}\right)$ i.e. $k=N^{\prime} / n^{\prime}$. Type 2 DM case flow in preceding month was 840 cases, sampling interval "k" =840/394 2 .

\section{Data collection tools and Procedure}

Data collections were conducted from July 15 to August 15, 2016 by interviewing type 2 adult DM patients using a pretested structured questionnaire. The questionnaire included questions that assessed dietary practice of patients. Dietary practice was assessed using the 11 item scale which was modified from the eight-item Morisky medication adherence scale (MMAS-8)(17). Components were computed by taking the mean value to classify the respondents as "good" and "poor". That is, those who scored below the mean value were classified as Good and those who scored above the mean value as poor dietary practices.

The questionnaire included questions that assess diabetic risk factors, demographic characteristics, monthly income, duration of diabetes, lifestyle, behavioral and social factors, health service related 
factors, barriers to adherence to dietary practice related factors, and diabetes knowledge. In addition, physical measurements were taken using standardized techniques and calibrated equipment. Height was measured using a stadiometer and weight was measured using digital weighting scale. Body mass index (BMI) was calculated as the ratio of weight in kilograms divided by the square of height in meters. Fasting Blood Glucose (FBG) of each participant was checked from finger capillary prick using senso card strip and glucometre by a trained laboratory technician following aseptic techniques. Dietary diversity of the subjects

was assessed using nine food groups; the standard questions were adopted from guidelines for measuring household and individual dietary diversity(18).

\section{Data management and Analysis}

Data were checked for completeness then entered using Epi-Info version 7 and exported to SPSS version 20 for further analysis. Bivariate analysis was used to check the association between independent variables and dietary practice. Logistic regression was applied to test the presence of association. The independent variables (covariates) were selected into the model based on prior evidence in the literature, conceptual framework, and their effect in current analysis. Independent variables with a p-value of 0.25 and less during the bivariate test were then included in the multivariable logistic regression model to include the marginal confounder. Independent variables in the model were monthly income, occupation, drug regimen, having chronic disease, having DM education in hospital, frequency of DM education, knowledge of optimum FBG level should achieve to prevent DM related complication, current body mass Index (BMI), knowledge for DM, despondency, lack of support of family and friends, poor understanding on food disease association, difficulty on availability of fruits and vegetables and high cost of foods. Values were then considered statistically significant when p-value is less than 0.05 at $95 \%$ $\mathrm{Cl}$. Frequency tables and texts were used for data presentation.

\section{Ethical considerations}

The study was ethically approved by the IRB (Institutional Review Board) at Hawassa University, College of Medicine and Health Science. At the time of data collection, informed verbal consent was taken from the participants to confirm their willingness to participate. The potential benefit in participating in the study was explained to all the participants. The participants were also informed about their rights to withdraw from the study at any time if they decide. Support letter was written from Hawassa University, School of Nutrition, Food Science and Technology and study was conducted after getting permission from Adare General Hospital Medical director and DM clinic coordinator.

\section{Results}

\section{Socio-Demographic and Economic Characteristics}


Out of the total 394 study participants planned, 387 were participated in the study yielding a response rate of $98.2 \%$. Of all respondents, 180 (46.5\%) and 207(53.5\%) were female and male, respectively. The majority of the study participants, 288 (74.4\%) were in the age group of 35 to 60 years. The mean $( \pm S D$ ) age of the respondents was $51.27 \pm 12.03$ with the minimum and maximum age of 18 and 90, respectively. Three hundred and seven (79.3\%) of the respondents are married. As for religion of the participants, 197 (50.9\%) belonged to Orthodox Christian, followed by Protestant Christian, 153(39.5\%). Larger populations were Amhara 134(34.6\%) followed by Sidama ethnic group, 105(27.1\%). Concerning the educational status of study subjects, a significant number, 298 (77.0\%) of the study population had attended formal education and 89 (23.0\%) were not able to read and write. Two hundred and sixty four (68.2\%) respondents were unemployed and majority of the study participants 250(64.6\%) had very low monthly income (Table 1 of supplementary material).

\section{Dietary practices}

From the total 394 study participants, the proportion of poor dietary practice was $171(44.2 \%)$. Nearly half of the participants $48 \%$ were forgetting to plan the meals they eat ahead and $37 \%$ of the participants were missed their dietary plan a day before interview. One hundred ninety four (50\%) of participant were experienced failing to keep dietary plan (Table 2 of supplementary material).

\section{Food groups consumed by type 2 DM patients}

The food groups consumed by adults with type 2 DM patients in the 24 hours preceding the survey are shown in Table 4.The proportion of DM patients who consumed foods from grains/starchy staple was found to be the highest $(97.4 \%)$ followed by foods from other vitamin A rich fruits and vegetables. Organ meat was consumed only by $1.6 \%$ of DM patients (Table 3 of supplementary material).

Characteristic of patients according to the groups of dietary practice

The proportions of participants with poor dietary practice were 78 (43.3\%) among males and $93(44.9 \%)$ among females. The proportion with poor dietary practice was $129(44.8 \%)$ among the age group of 35-60, and 32(41.0\%) among those who were 61 and above years old (Table 4 of supplementary material).

Health status and available health services 
About half of the respondents 195(50.4\%) had $>3$ years duration of diabetic disease. The median duration since the diagnosis of diabetes was reported to be 4 years. Two hundred forty-nine (64.3\%) of respondents were on oral hypoglycemic regimen, 113 $(29.2 \%)$ were on insulin and $2(0.5 \%)$ were on only following dietary plan as recommended. About 161(41.6\%) of the respondents had chronic disease other than diabetics. The majority $291(75.2 \%)$ of the respondents reported that they did not receive nutrition education in hospital and a large number did not get nutrition leaflet.

More than half of the respondents $211(54.5 \%)$ were with BMI of $>=25 \mathrm{~kg} / \mathrm{m}^{2}$ and the majority of the respondents 314 (81.1\%) had Fasting Blood Glucose of $\geq 126 \mathrm{mg} / \mathrm{dl}$ (Table 5 of supplementary material).

\section{Barriers to adherence to dietary regimen}

Concerning barriers to adherence, 275(71.1\%) of the respondents said that foods were not prepared based on their disease. Furthermore, 278(71.8\%) of the respondents had difficulty of choosing foods and $231(59.7 \%)$ of the respondents reported nonavailability of fruits and vegetables. Price of food items and lack of support from family and friends were the two most important barriers to adhere to dietary regimen for $260(67.2 \%)$ and $114(29.5 \%)$ of the respondent respectively (Figure 1 of supplementary material).

\section{Behavioral and Social Conditions of Participants}

The majority, 239(61.8\%) of the responded said that they have not made food choice when eating out of their home. Most of the respondents, 284(99.2\%), and 351(90.7\%) replied that they have no smoking and drinking habits, respectively. Furthermore, $47(12.1 \%)$ of the participants replied that they have experience of despondency. More than half of the respondents $235(60.7 \%)$ did not participate in physical activity and 384(99.2\%) did not check their FBG on daily basis (Figure 1).

\section{Respondents' knowledge about diabetes}

Knowledge of the participant about diabetes was measured by using nine variables with 24 possible correct responses. The mean $( \pm S D)$ knowledge score of study subjects was 11.05(6.20) with a maximum possible score of 24 . Two hundred six (53.2\%) participants had good knowledge and 181 (46.8\%) participants had poor knowledge regarding diabetes. More than half (53.5\%) of study subjects didn't know the definition of diabetes. The correct responses on risk factor for diabetes like family history, eating too much fat and sugar, and lack of exercise were $59.9 \%, 49.1 \%, 0.3 \%$ respectively. 
Majority of the study participants 327 (84.5\%) and 324(83.7\%) considered injection/insulin therapy and orally taken tablets as treatment options, respectively. Passing lots of urine, excessive thirsty, tiredness and weight loss were reported as symptom of poorly controlled DM by 213(55.05\%), 167(43.2\%), 292(75.5\%) and 47(12.1\%) respondents respectively. The correct responses on complication of DM like retinopathy, hypoglycemia, nephropathy, and neurologic were $57.9 \%, 14.5 \%, 52.5 \%$ and $38.2 \%$ respectively. Exercise and diet were reported as a life style modification for prevention of DM by 197(50.9\%) and 245(63.3\%) respondents respectively. However, less than $25.0 \%$ of study participants knew weight reduction as life style modification for prevention of diabetes related complications.

Nearly three fourth (69.5\%) of study participants knew about the importance of control of blood glucose to reduce complication of DM. Two hundred seventy eight (71.8\%) knew the importance of control of blood pressure for prevention of DM complications. Less than one third (30.7\%) of the participants did know about optimum blood sugar level they should be achieve to prevent DM (Table 1).

Table 1:Knowledge of participants regarding diabetes mellitus, Adare General Hospital Hawassa City, Ethiopia , Ethiopia, 2016 ( $\mathrm{n}=387$ ) 


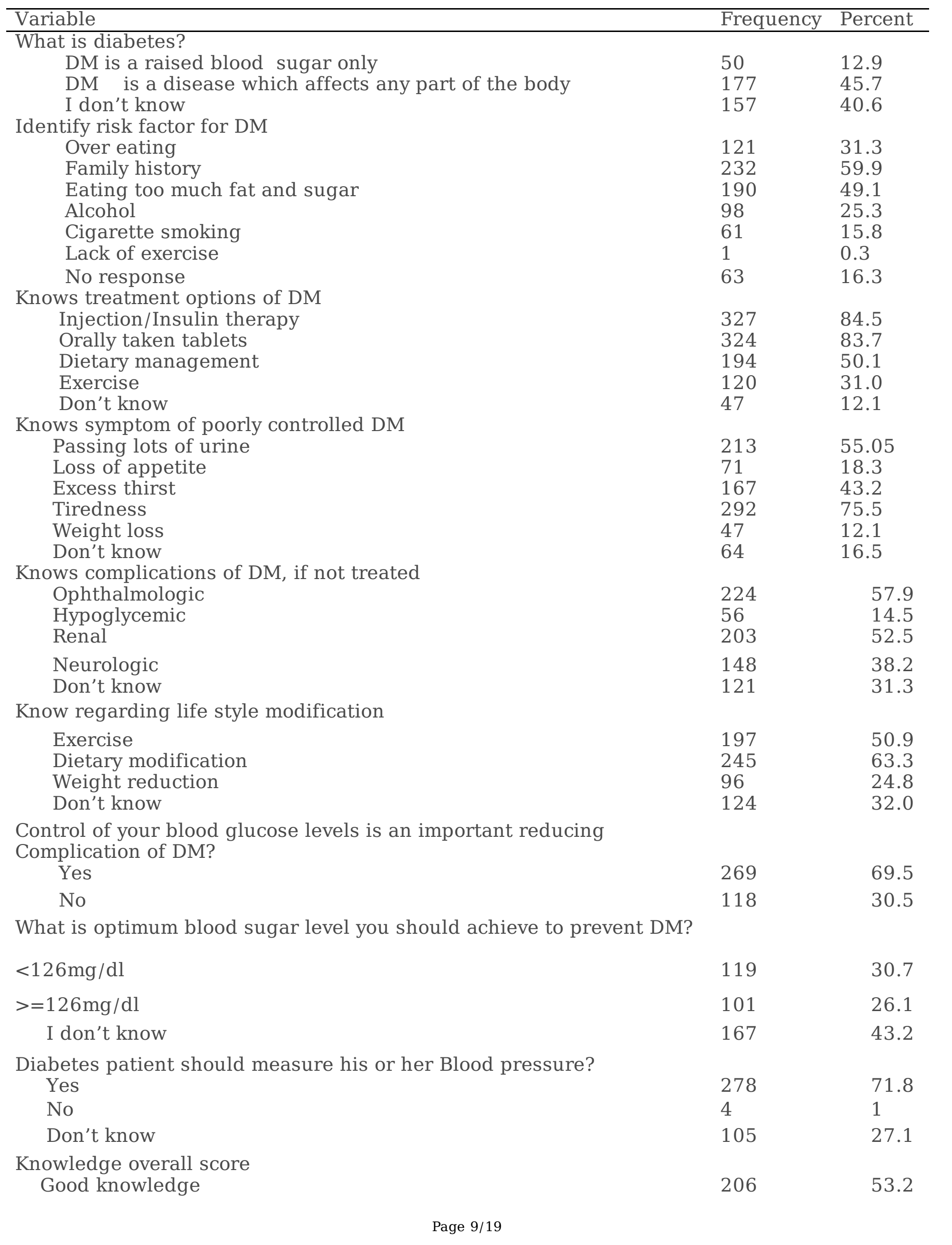


With mean knowledge of 11.05 and SD is 6.201 and maximum response is 21 and minimum response is 0 and with possible correct response is 24 (9 tools)

Factors associated with the dietary practice of type 2 diabetic patients

An output from a bivariate analysis showed that there are significant associations between dietary practice and various attributes such as: monthly income, occupation, drug regimen, having chronic disease, DM education in hospital, and frequency of DM education. All characteristics with p-value of at most 0.25 in bivariate analysis, such as, knowledge of optimum FBG level, body mass Index (BMI), knowledge about-DM, despondency, lack of support from family and friends, poor understanding on diet disease association, difficulty on availability of fruits and vegetables and price of diet items were entered into the final multivariable logistic regression model to control for potential confounders and significant association at a $5 \%$ level of significance was reported.

The multivariable logistic regression analysis showed that those who had very low monthly income were 4.87 times more likely to have poor dietary practice than those who had average income $(\mathrm{AOR}=4.87 ; 95 \% \mathrm{CI}$ : $(1.20$-19.81). Subjects who take insulin regimen were 2.36 times more likely to follow poor dietary practice than those who take only oral DM medication (AOR=2.36; 95\%CI: 1.13 - 4.91) and those who took both insulin injection and oral medication were 11.26 time more likely to follow poor dietary practice than those who take only oral DM medication (AOR=11.26; 95\% CI: (3.05 - 41.54). With regard to education, those who didn't get DM education were 2.72 times more likely to have poor dietary practice than those who got $(\mathrm{AOR}=2.72 ; 95 \% \mathrm{CI}:(1.08-6.85)$ and who did get DM education for less than 2 times were 5.88 times more likely to follow poor dietary practice compared to those who got dietary education twice or more (AOR=5.88; 95\% CI: 1.88 -18.88). Respondents who had despondency were 3.71 times more likely to follow poor dietary practice than those who did not have despondency (AOR $=3.71 ; 95 \%$ CI: (1.39 9.89).

Respondents who had lack of support from family and friends were 5.64 time more likely to follow poor dietary practice than those who had support (AOR=5.64; 95\% CI: 2.66 -11.92). Likewise, patients who had less access to fruits and vegetables were 3.04 times more likely to have poor dietary practice than those who did not (AOR $=3.04 ; 95 \%$ CI: 1.11-8.34) (Table 3).

Table 2:Bivariate and Multivariable Logistic Regression Analysis of Factors Associated With Dietary Practice of Type 2 Diabetic Patients in Adare General Hospital Hawassa 
City, Ethiopia, $2016(\mathrm{~N}=387)$

\begin{tabular}{|c|c|c|c|c|}
\hline \multirow[t]{2}{*}{ Variables } & \multicolumn{2}{|c|}{ Dietary practice } & \multirow{2}{*}{$\begin{array}{l}\text { COR }(95 \% \\
\text { CI) }\end{array}$} & \multirow{2}{*}{$\begin{array}{l}\text { AOR }(95 \% \\
\text { CI) }\end{array}$} \\
\hline & Poor & Good & & \\
\hline \multicolumn{5}{|l|}{ Monthly Income } \\
\hline Very low & $135(54.0 \%)$ & $115(46.0 \%)$ & $4.11(2.24-$ & $4.87(1.20-$ \\
\hline Low & $10(34.5 \%)$ & $19(65.5 \%)$ & $7.55)^{*}$ & $19.81)^{* *}$ \\
\hline Average & $10(27.8 \%)$ & $26(72.2 \%)$ & $1.84(0.72-$ & $1.32(0.27-$ \\
\hline Above Average & $16(22.2 \%)$ & $56(77.8 \%)$ & $4.74)$ & $6.43)$ \\
\hline & & & $1.35(0.54-$ & $1.05(0.27-$ \\
\hline & & & 3.37) & $4.00)$ \\
\hline \multicolumn{5}{|l|}{ Occupation } \\
\hline Employed & $34(33.3 \%)$ & $68(66.7 \%)$ & 1 & 1 \\
\hline Unemployed & $132(50.0 \%)$ & $132(50.0 \%)$ & $2.00(1.24-$ & $0.53(0.14-$ \\
\hline Merchant & $5(23.8 \%)$ & $16(76.2 \%)$ & $3.22)^{*}$ & $2.00)$ \\
\hline & & & $0.63(0.21-$ & $0.39(0.07-$ \\
\hline & & & 1.85) & \\
\hline \multicolumn{5}{|l|}{ Drug regimen currently } \\
\hline Oral DM medication & $92(36.9 \%)$ & $157(63.1 \%)$ & 1 & 1 \\
\hline Insulin & $58(51.3 \%)$ & $55(48.7 \%)$ & $1.80(1.14-$ & $2.36(1.13-$ \\
\hline Insulin \& Oral & $19(82.6 \%)$ & $4(17.4 \%)$ & $2.82)^{*}$ & $4.91)^{* *}$ \\
\hline Only Diet plan & $2(100 \%)$ & $0(0.0 \%)$ & $8.12(2.67-$ & $11.26(3.05-$ \\
\hline & & & $24.5)^{*}$ & $41.54)^{* *}$ \\
\hline & & & $0.00(0.00-$ & $0.00(0.00-$ \\
\hline & & & ) & ) \\
\hline \multicolumn{5}{|l|}{ Having Chronic Disease } \\
\hline Yes & $82(50.9 \%)$ & $79(49.1 \%)$ & $1.60(1.06-$ & $1.79(0.92-$ \\
\hline No & $89(39.4 \%)$ & $137(60.6 \%)$ & $2.40)^{*}$ & $3.50)$ \\
\hline & & & 1 & 1 \\
\hline \multicolumn{5}{|c|}{$\begin{array}{l}\text { Ever attended DM Education in } \\
\text { Hospital }\end{array}$} \\
\hline Yes & $29(15.6 \%)$ & $157(84.4 \%)$ & 1 & 1 \\
\hline No & $142(70.6 \%)$ & $59(29.4 \%)$ & $13.03(7.91-$ & $2.72(1.08-$ \\
\hline \multirow{2}{*}{\multicolumn{5}{|c|}{ Number of DM Education in one year }} \\
\hline & & & & \\
\hline$=<2$ times & $159(93.0 \%)$ & $91(42.1 \%)$ & $18.20(9.54-$ & $5.88(1.83-$ \\
\hline$>2$ times & $12(7.0 \%)$ & $125(57.9 \%)$ & $34.72)^{*}$ & $18.88)^{* *}$ \\
\hline \multirow{2}{*}{\multicolumn{5}{|c|}{$\begin{array}{l}\text { Optimum FBG level should achieve to } \\
\text { prevent DM related Complication }\end{array}$}} \\
\hline & & & & \\
\hline$<126 \mathrm{mg} / \mathrm{dl}$ & $53(44.5 \%)$ & $66(55.5 \%)$ & 1 & 1 \\
\hline$>=126 \mathrm{mg} / \mathrm{dl}$ & $12(11.9 \%)$ & $89(88.1 \%)$ & $4.14(2.70-$ & $2.56(0.99-$ \\
\hline \multicolumn{5}{|l|}{ Knowledge for DM } \\
\hline Good Knowledge & $68(31.5 \%)$ & $148(68.5 \%)$ & 1 & 1 \\
\hline Poor Knowledge & $113(66.1 \%)$ & $58(33.9 \%)$ & $4.24(2.76-$ & $1.65(0.64-$ \\
\hline \multirow{2}{*}{\multicolumn{5}{|c|}{ Despondency }} \\
\hline Yes & $37(787 \%)$ & $10(213 \%)$ & & \\
\hline No & $134(39.45)$ & $\begin{array}{l}10(21.3 \%) \\
206(60 \% \%)\end{array}$ & $5.69(2.74-$ & 3.71(1.39- \\
\hline & & & 1 & \\
\hline
\end{tabular}


*Statistically associated Variable with; $\mathrm{P}=<0.25$; NB: P-Value is, Value of COR analysis result ** Statistically associated Variable with; $\mathrm{P}=<0.05$; NB: P-Value is, Value of AOR analysis result

Table 3:Bivariate and Multivariable Logistic Regression Analysis of Barriers affecting dietary practice of type 2 diabetic patients in Adare General Hospital Hawassa City, Ethiopia, $2016(\mathrm{n}=387)$

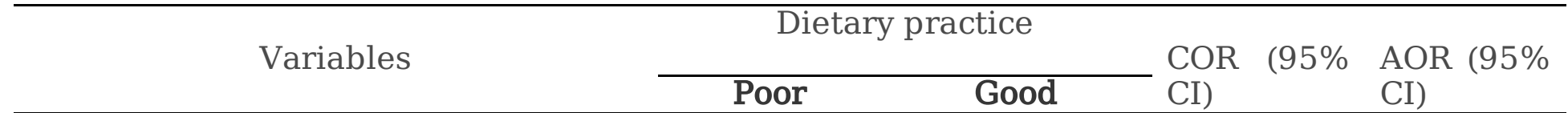

Challenge on food preparation based on DM status

$\begin{array}{llll}\text { Yes } & 117(42.5 \%) & 158(57.5 \%) & 0.79(0.51- \\ \text { No } & 54(48.2 \%) & 58(51.8 \%) & 1.24) \\ & & & 1\end{array}$

Difficulty on choosing foods

$\begin{array}{llll}\text { Yes } & 120(43.2 \%) & 158(56.8 \%) & 0.86(0.55- \\ \text { No } & 51(46.8 \%) & 58(53.2 \%) & 1.35) \\ & & & 1\end{array}$

Lack of support of family and friends

$\begin{array}{cllll}\text { Yes } & 92(80.7 \%) & 22(19.3 \%) & \mathbf{1 0 . 2 7 ( 6 . 0 2 -} & \mathbf{5 . 6 4 ( 2 . 6 6 -} \\ \text { No } & 79(28.9 \%) & 194(71.1 \%) & \mathbf{1 7 . 5 1})^{*} & \mathbf{1 1 . 9 2})^{* *} \\ & & & 1 & 1\end{array}$

Poor understanding on food $\mathrm{d} / \mathrm{s}$ association

$\begin{array}{lllll}\text { Yes } & 79(66.4 \%) & 40(33.6 \%) & \mathbf{3 . 7 8 ( 2 . 3 9 -} & 1.15(0.55- \\ \text { No } & 92(34.3 \%) & 176(65.7 \%) & \begin{array}{l}\mathbf{5 . 9 6})^{*} \\ 1\end{array} & \begin{array}{l}2.40) \\ 1\end{array} \\ & & & & \\ \text { M by food planning? } & & & & 1 \\ \text { Yes } & 126(73.7 \%) & 180(83.3 \%) & 1 & 1 \\ \text { No } & 45(26.3 \%) & 36(16.7 \%) & \mathbf{1 . 7 9 ( ( 1 . 0 9 -} & 0.75(0.30- \\ & & & \mathbf{2 . 9 3})^{*} & 1.86)\end{array}$

Difficulty on availability of fruits and vegetables

$\begin{array}{lllll}\text { Yes } & 141(61.0 \%) & 90(39.0 \%) & \mathbf{6 . 5 8 ( 4 . 0 8 -} & \mathbf{3 . 0 4 ( 1 . 1 1 -} \\ \text { No } & 30(19.2 \%) & 126(80.8 \%) & \mathbf{1 0 . 6 1})^{*} & \mathbf{8 . 3 4})^{* * *} \\ & & & 1 & 1\end{array}$

High cost of foods

\begin{tabular}{lllll} 
Yes & $147(56.5 \%)$ & $113(43.5 \%)$ & $\mathbf{5 . 5 8 ( 3 . 3 6 -}$ & $1.03(0.33-$ \\
No & $24(18.9 \%)$ & $103(81.1 \%)$ & $\begin{array}{l}\mathbf{9 . 2 7})^{*} \\
1\end{array}$ & $3.20)$ \\
\hline
\end{tabular}


*Statistically associated Variable with; $\mathrm{P}<0.25$ NB: P-Value is, Value of COR analysis result

** Statistically associated Variable with; $\mathrm{P}<0.05$ NB: P-Value is, Value of AOR analysis result

\section{Discussion}

Diabetes dietary practice depends on guidance from a health care provider, meal preparation in a family context and exercising with a partner or in a group. The study showed that nearly half proportion of type 2 DM patients had poor dietary practice. Very low monthly income, drug regimen like insulin only and insulin with oral medication, not getting DM education in hospital, less frequency of DM education in one year, despondency, lack of support of family and friends, and difficulty on availability of fruits and vegetables were the variables identified for having significant associations with poor dietary practice.

The overall occurrence of poor dietary practice among type 2 diabetic patients at Adare General Hospital was found to be $44.2 \%$. Similar study done on dietary practice and associated factors among type 2 DM patients in Yekatit 12 Medical College Hospital, Addis Ababa has indicated that $51.4 \%$ of the patients had poor dietary practice(19). Another study done in Tikur Anbessa Specialized Hospital showed that 79 $\%$ of the study participants did not adhere to recommended dietary management practices which is higher than the finding of the present study(20). This variation could be due to difference in sample size, difference in educational background, and the role of current strong association of diabetic patients in the study area. Another study done in Uganda on the factors affecting adherence to nutrition therapy found that the practice of recommended nutrition therapy for $62.9 \%$ of the diabetic patients was low, which is higher than the finding of present study(21). The disparity could be explained by the variation in the settings of the study, difference in the socioeconomic and socio-demographic characteristics, different in study instrument used, number of study participants, study design used as well as difference in the types of foods available in the two nations. Studies done on the assessment of dietary practice among diabetic patients in the United Arab Emirates and Riyadh, Saudi Arabia also reported inadequate dietary practice(22) (23).

This study identified that monthly income was one of the factor significantly associated with dietary practice. In this finding, $64.6 \%$ of respondents had very low monthly income and were 4.87 times more likely to have poor dietary practice than those who had above average monthly income. This is similar with studies done among adult diabetic patients in Harar and Nekemte Hospitals regarding self-care practices(24) (1).This, may show that patients relatively in high income category can get healthy foods that are recommended for diabetic patients. This finding is consistent with other study conducted in Malaysia on self-care practices of Malaysian adults with diabetes(25). In clear terms, those who have low monthly income cannot afford to buy different types of foods to fulfill their daily requirements for maintaining good dietary practice. Therefore, they will be forced to consume only some specific foods without choice and get exposed to poor self-dietary management.

Drug regimen like insulin only and insulin with oral medication were other factors affecting the dietary practice. Possible explanation is that the complexity of treatment and duration of disease may lead 
patients to frustration not to keep recommended dietary practice since most of the time in type 2 DM patient's insulin and insulin with oral medication are treatment option after long time use of oral medication.

Lack of education about diabetes at hospitals and less frequent DM education per year were associated with the poor dietary practice of the patients. This is consistent with study done on the assessment of dietary practice among diabetic patients in Yekatit 12 Medical College Hospital, Addis Ababa(19) and study done in South Africa which has identified the need for nutrition education related to diabetes care for optimal diabetes management(26). This may be due to the fact that those who get nutrition education and who get more frequent nutrition education follow the advices from clinicians and have better knowledge and understanding about the foods suitable for condition of their disease, food guides and prescriptions than those who don't get nutrition education.

Despondency was another factor identified to associate with poor dietary practice. Respondents who had despondency were 3.71 times more likely to follow poor dietary practice than those who did not have despondency. This result is in agreement with reports that showed coexisting despondency in people with diabetes is associated with decreased adherence to dietary management DM (27) (17). Accordingly, those who were despondency for most of the times were two to three times highly at risk of forgetting and not giving value to food planning and therefore, consume whatever is edible.

Lack of support from family and friends was another factor affecting the dietary practice of diabetic patients. Respondents who had lack of family and friends support were nearly six times more likely to follow poor dietary practice than those who had support. This result is in agreement with the study done in USA on predictors of self-care behaviors in adults with type 2 diabetes(8) (28). This may be due to lack of awareness and insufficient knowledge about dietary regimen of diabetes among families and friends.

On the other hand, the findings from this study contradict the study conducted in Yekatit 12 Medical College Hospital, Addis Ababa(19). These researchers, who examined the dietary practice and associated factors among type 2 diabetes, found that social support was not associated with poor dietary practice of diabetes patients. The differences in results between this study and the present study could be due to variation in the settings of the study and difference in socio-demographic characteristics.

Non availability of fruits and vegetables was another factor affecting the dietary practice of diabetic patients. This result is in line with a report on creating healthy food and eating environments in the United States of America(28). This may be due to the seasonality of fruits and vegetables which make the patients suffer from difficulty to take the recommended type and amount of fruits and vegetables, leading to poor dietary practice.

\section{Practical implications of the finding}

Compliance to glycemic control and diabetes dietary practice is a major problem in peoplewith diabetes, especially among individuals with or at risk of developing diabetes-related complications. Therefore, 
addressing the factors examined in this study may possibly enhance dietary practice of Type 2 DM patients. Health intervention developers, dieticians, nutritionists, educators, health psychologists, physicians, nurses, and other clinicians will find it useful in the creation and utilization of holistic intervention in order to improve diabetes dietary practices of Adare General Hospital population with T2DM.

This study also offers support for educating clients with diabetes and their family members about the connections between self-efficacy, spirituality, family, and social support in diabetes dietary practice. When properly managed, progression of diabetes will be delayed and complications will likely be prevented, thereby benefitting the patients and their families through reduced financial burdens, decreased morbidity, and lessened mortality. In addition, more investigation is needed from physicians, nurses, and dietitians about dietary practice and habits of T2DM patients, and in the methods used for developing solutions to overcome these potential barriers when counseling patients. This cross-sectional study was one of the first studies able to provide an overview specifically on the level of dietary practice and factors associated with dietary practice T2DM patients. Finally, the findings of this study will help Regional Health Bureau and Zonal Health Department to develop health information dissemination programs and strategies to alleviate these potential barriers for management of DM with diet.

\section{Limitation of the study}

Findings of this study should be interpreted within several limitations. The design is a cross-sectional rather than longitudinal; therefore, may not show temporal relationships of potential risk factors with dietary practice. The assessment of dietary practices was based on self-reported dietary habits rather than direct observation. This may led to under reporting of socially undesirable responses and recall bias. Using self-reported dietary practice as a measure of the level of practice may introduce social desirability bias.

\section{Conclusions}

This study showed that the prevalence of poor dietary practices was forty-four percent among type 2 DM patients. It is therefore, a major public health problem. Very low monthly income, Drug regimen like insulin only and insulin with oral medication, Not getting DM education in hospital, low frequency of DM education in one year, Despondency, Lack of support of family and friends, and Difficulty on availability of fruits and vegetables were important factors affecting dietary practice of type 2 diabetic patients. As for recommendation, it is vital to take into consideration the following facts to improve the situation of diabetic patients: Regional Health Bureau and Zonal Health Departments should have to develop health information dissemination programs and strategies that consider the low educational status, occupational background, average low monthly income to improve the awareness of diabetic patients about diabetes and the importance of management of DM with diet. Prepare routine health information dissemination and should be given by trained and experienced health professional by considering the patients educational background, occupation, age, years of suffering from the disease. Family members should be informed about their important roles in encouraging patients to undergo DM management with 
diet. Media and non-government organization involvement to enhance knowledge and practice about DM is highly recommended. Finally, further study which could see the association longitudinally is also recommended

\section{Abbreviations}

\begin{tabular}{ll} 
BMI: & Body Mass Index \\
\hline DM: & Diabetes Mellitus \\
\hline FBG: & Fasting Blood Glucose \\
\hline IDF: & International Diabetes Federation \\
\hline IRB: & Institutional Review Board \\
\hline MMAS: & Morisky medication adherence scale \\
\hline SD: & Standard Deviation \\
\hline T2DM: & Type 2 Diabetes Mellitus \\
\hline WHO: & World Health Organization
\end{tabular}

\section{Declarations}

Acknowledgements

The researchers are very grateful and would like to extend my heartfelt thanks to all staff members of School of Nutrition, Food Science and Technology, Adare General Hospital Medical Director, DM clinic Staffs, data collectors, supervisors and study groups for their valuable contribution and giving me pertinent information for accomplishment of the research project.

Authors Contributions

MGM is principal investigator, designed the study, took part in the data collection, entered \& analyzed the data and wrote the manuscript of the current study. $\mathrm{DH}$ and $\mathrm{MZ}$ did participate in data analysis, and write up. DTD oversaw and gave comment and suggestion during the manuscript write up. The authors read and approved the final manuscript to be submitted.

Funding

Not Applicable

Ethical Approval 
Approval of the research was given by Hawassa University Institutional Review Board (IRB). Prior to data collection the district administrators were contacted with a description of the study and purposes and consent was taken. The nature of the study was fully explained to the respondent and oral consent was taken ahead of interview.

Consent for publications

Not applicable for this section

Availability of Data and Materials

The datasets used and/or analysed during the current study are available from the corresponding Author on reasonable request

\section{References}

1. Tadele Amente, Tefera Belachew, Endalew Hailu and NB. Self care practce and its predictors among adults withdiabetes mellitus on follow up at Nekemte Hospital. World J Med Med Sci [Internet]. 2014;2(3):1-16. Available from: http://www.wjmms.com

2. Hoff AL, Wagner JL, Mullins LL, Chaney JM. Behavioral management of type 2 diabetes. Heal Psychol Handb Pract issues Behav Med Spec. 2003;303-24.

3. Shaw JE, Sicree RA, Zimmet PZ. and Clinical Practice Global estimates of the prevalence of diabetes for 2010 and 2030. diabetes Res c linical p ractice. 2010;87(2010):4-14.

4. Whiting DR, Guariguata L, Weil C, Shaw J. IDF diabetes atlas: global estimates of the prevalence of diabetes for 2011 and 2030. Diabetes Res Clin Pract. 2011 Dec;94(3):311-21.

5. Guariguata L, Whiting DR, Hambleton I, Beagley J, Linnenkamp U, Shaw JE. Global estimates of diabetes prevalence for 2013 and projections for 2035. Diabetes Res Clin Pract. 2014 Feb;103(2):137-49.

6. Fowler MJ. Diagnosis, classification, and lifestyle treatment of diabetes. Clin Diabetes. 2010;28(2):79-86.

7. Ekore R, Ajayi IO, Ekore JO. Dietary management of diabetes: a practical approach for primary care physicians in Nigeria. Mera Diabetes Int. 2007;(November):13-4.

8. U.S. Department of Health and Human ServicesCenters for Disease Control anmd Prevention. National Diabetes Statistics Report. 2020. Estimates of Diabetes and Its Burden in the United States. 2020;

9. Harris MI. Frequency of blood glucose monitoring in relation to glycemic control in patients with type 2 diabetes. Diabetes Care. 2001;24(6):979-82.

10. World Health Organization of United Nations. Definition, Diagnosis and Classification of Diabetes Mellitus and its Complications. Geneva; 1999. 
11. A. S. Fauci, D. L. Kasper, D. L. Longo, E. Braunwald, S. L. Hauser, J. L. Jameson and J. Loscalzo Macdonald G. Harrison's Internal Medicine, 17th edition [Internet]. Vol. 38, Internal Medicine Journal. John Wiley \& Sons, Ltd; 2008. 932 p. Available from: https://doi.org/10.1111/j.14455994.2008.01837.x

12. Mbanya JCN, Motala AA, Sobngwi E, Assah FK, Enoru ST. Diabetes in sub-Saharan Africa. Lancet (London, England). 2010 Jun;375(9733):2254-66.

13. Seyoum B, Abdulkadir J, Gebregziabher F, Alemayehu B. Analysis of diabetic patients admitted to Tikur Anbessa Hospital over eight years period. Ethiop J Heal Dev. 1999;13:9-14.

14. Abebe SM, Berhane Y, Worku A, Alemu S. Increasing Trends of Diabetes Mellitus and Body Weight: A Ten Year Observation at Gondar University Teaching Referral Hospital, Northwest Ethiopia. PLoS One. 2013;8(3):10-3.

15. Feleke Y, Enquselassie F. Cost of hospitalization of diabetic patients admitted at Tikur Anbessa Specialized Hospital, Addis Ababa, Ethiopia. Ethiop Med J [Internet]. 2007 Jul;45(3):275-282. Available from: http://europepmc.org/abstract/MED/18330328

16. Yemane T, Belachew T, Asaminew B BO. Type II Diabetes Mellitus in Jimma Town South West Ethiopia. Ethiop Heal Sci. 2007;17(02):107-14.

17. Donald E. Morisky, Robin MD. Improving the measurement of self-reported medication nonadherence: Response to Authors. J Clin Epidemiol. 2011;64(3).

18. Food and Agriculture Organization of the United Nations. Guidelines for measuring household and individual dietary diversity. 2011.

19. Worku A, Mekonnen Abebe S, Wassie MM. Dietary practice and associated factors among type 2 diabetic patients: a cross sectional hospital based study, Addis Ababa, Ethiopia. Springerplus. 2015;4(1):1-8.

20. Kidanu Berhe K, Demissie A, Kahsay AB, Gebru HB. Diabetes Self Care Practises And Associated Factors Among Type 2 Diabetes Patinents In Tikur Anbessa Specialized Hospital, Addis Ababa, Ethiopia -A Cross Sectional Study. ljpsr [Internet]. 2012;3(11):4219-29. Available from: www.ijpsr.com

21. Kalyango JN, Owino E, Nambuya AP. Non-adherence to diabetes treatment at Mulago Hospital in Uganda: prevalence and associated factors. Afr Health Sci. 2008;8(2):67-73.

22. Juma Al-Kaabi, Fatma Al-Maskari, Hussein Saadi BA, Parkar H, Nagelkerke and N. Assessment of Dietary Practice Among Diabetic Patients in the United Arab Emirates. Rev Diabet Stud. 2008;5:1105.

23. Mohamed BA, Almajwal AM, Saeed AA, Bani IA. Dietary practices among patients with type 2 Diabetes in Riyadh Saudi Arabia Dietary practices among patients with type 2 diabetes in Riyadh, Saudi Arabia. J Food, Agric Environ. 2015;11(2):110-4.

24. Ayele K, Tesfa B, Abebe L, Tilahun T, Girma E. Self Care Behavior among Patients with Diabetes in Harari, Eastern Ethiopia : The Health Belief Model Perspective. PLoS One. 2012;7(4):e35515. 
25. Tan MY, Magarey J. Self-care practices of Malaysian adults with diabetes and sub-optimal glycaemic control. Patient Educ Couns. 2008 Aug;72(2):252-67.

26. Albright TL, Parchman M, Burge SK. Predictors of Self-care Behavior in Adults With Type 2 Diabetes: An RRNeST Study. Fam Med. 2001;13(5):354-60.

27. Story M, Kaphingst KM, Brien RR, Glanz K. Creating Healthy Food and Eating Environments: Policy and Environmental Approaches. Annu Rev Public Heal. 2008;29:253-72.

28. Report MW. National Diabetes Month - November 2012 Diabetes Death Rates Among Youths Aged $\leq 19$ Years - United States, 1968-2009. 2012;61(43):2008-10.

\section{Figures}

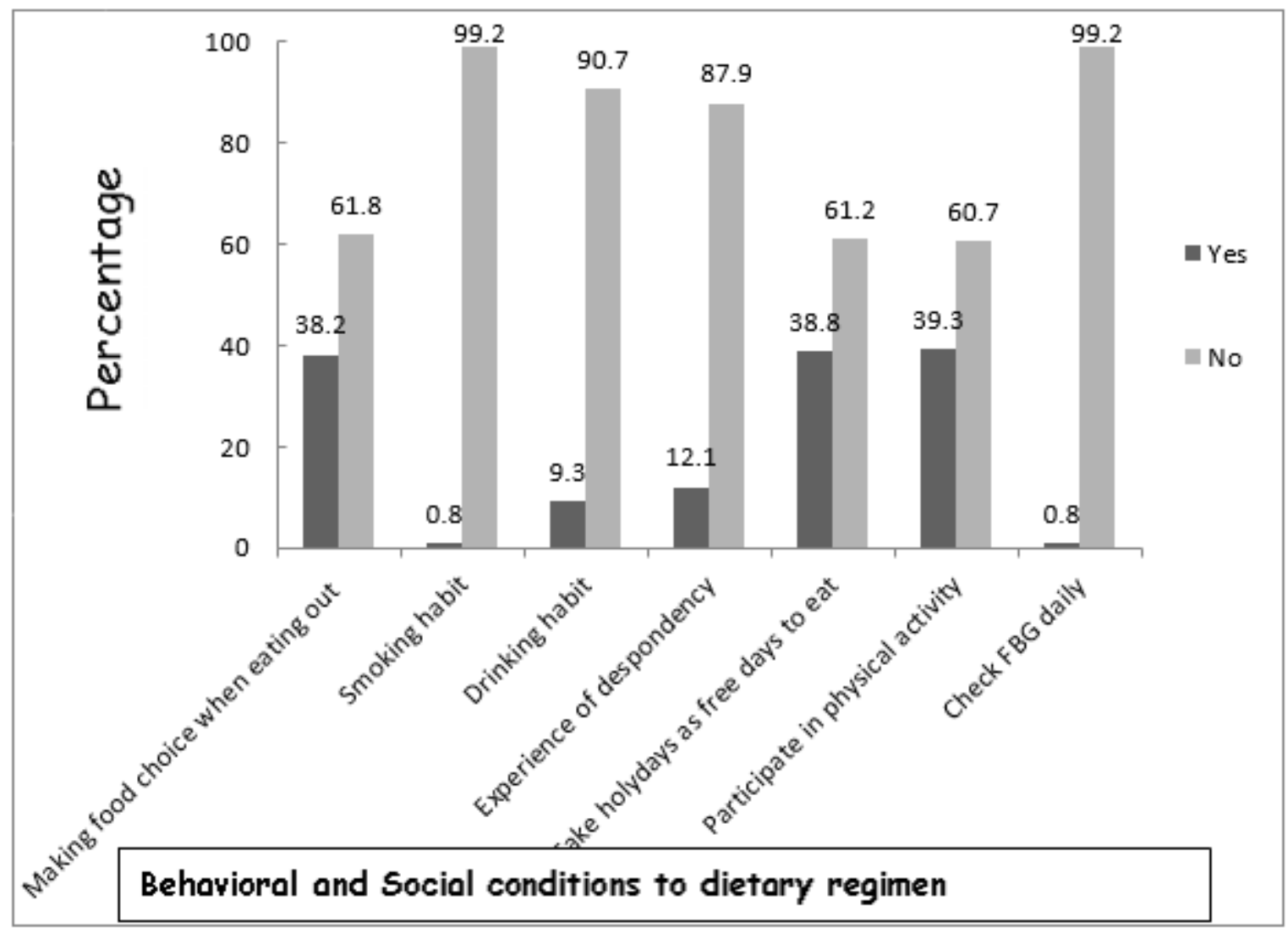

Figure 1

Behavioral and Social conditions to dietary regimen of type 2 diabetic patients in Adare General Hospital, Hawassa City, Ethiopia, $2016(n=387)$

\section{Supplementary Files}

This is a list of supplementary files associated with this preprint. Click to download.

- SupplementarymaterialsBMCresearchnote.docx 